\title{
Study on Big Data-based Behavior Modification in Metro Construction
}

\begin{abstract}
With the rapid development of metro construction in China, construction accidents frequently happen, which are significantly attributable to workers' unsafe behavior. Behavior-based safety (BBS) is an effective method to modify workers' unsafe behavior. This paper introduces the study on big data-based metro construction behavior modification, aiming to solve the problem of current research without consideration of workers' personal characters. First, the behavior modification pushing mechanism based on content-based personalized recommendation is studied. Secondly, the development of behavior modification system of metro construction (BMSMC) is introduced. Thirdly, BMSMC practical applications using the unsafe behavior rate, $S$ as a measuring indicator is implemented. Observations at one metro construction site in Wuhan indicate that the unsafe behavior rate of modified scaffolders at this work place decreased by $69.3 \%$. At the same time, as of unmodified scaffolders at another work place for comparison, the unsafe behavior rate decreased by $56.9 \%$, which validates the effectiveness of this system.
\end{abstract}

Keywords: big data, unsafe behavior, behavior modification, behavior-based safety (BBS), unsafe behavior rate

\section{Introduction}

Urban rail transit system in China has been blooming from the beginning of the 21st century. Up to June 2014, the central government of China had approved the metro construction programs for 36 cities, including Beijing, Shanghai, etc. The total mileage is expected to increase to over $8,500 \mathrm{~km}$ in 2020 from about $3,100 \mathrm{~km}$ currently (Zhou, 2014). Taking Wuhan (one of the biggest cities in

Manuscript received February 1, 2015; accepted May 15, 2015

Lie-yun Ding ( $\varangle$ ), Sheng-yu Guo

Institute of Construction Management, Huazhong University of Science and Technology, Wuhan 430074, China

Email: dly@hust.edu.cn
China) for example, the metropolitan is undergoing a period of rapid metro construction, with nine metro lines under construction in 2015 (Liu, 2015). In this case, the inprogress construction thus becomes extremely risky due to the considerable labor intensity and construction speed. In other words, construction with sites in confined spaces and a complex construction environment, might lead to more frequent construction accidents. Heinrich, Petersen, \& Roos (1950) found that $88 \%$ of accidents were caused by worker's unsafe behavior after studying nearly 75,000 cases. Lingard \& Rowlinson (2005) also emphasized that $80 \%-90 \%$ of accidents were caused by unsafe behavior. Therefore, the mechanism of behavior modification should be implemented so as to control worker's unsafe behavior, enhancing the safety management in metro construction and reducing the rate of accident.

Behavior-based safety (BBS), which has been widely used in construction industry (Chen \& Ren, 2015; Li, Lu, Hsu, Gray, \& Huang, 2015; Lingard \& Rowlinson, 1997; Smith, 1999) is an effective approach to guide and motivate behavior modification (Geller, 2000), aiming to increase worker's safe behavior and decreasing worker's unsafe behavior. BBS research currently focuses on several aspects, such as using intelligent sensing devices to automatically obtain and classify worker's behavior for machine observation (Azar \& McCabe, 2012; Han \& Lee, 2013; Shrestha, Shrestha, Bajracharya, \& Yfantis, 2015; Teizer \& Vela, 2009), combining the traditional BBS with contemporary information management system to improve its effectiveness (Li, Lu, Hsu, Gray, \& Huang, 2015; Zhang \& Fang, 2013), as well as improving the sustainable effectiveness of BBS application on construction sites (Choudhry, 2014). However, there are few studies on the method of workers' behavior modification, which only uses on-site interviews, meetings or trainings without insightful investigation into the effective mechanism of behavior modification. Metro construction workers include steel bar setters, scaffolders, etc. Due to differences of experience, construction tasks and so on, different types of workers may form different unsafe behaviors in different phases, therefore personalization should be imposed in behavior modification. 
On the other hand, with the popularization of personal computers, smart phones and other devices in worldwide scale and a growing amount of Internet access in the emerging markets, the concept of big data has come into being, which means a collection of data sets so large and complex as to become much more difficult to process using traditional database management tools or traditional data processing applications (Mayer-Schönberger \& Cukier, 2013). The global data in 2020 will increase to more than 35 ZB (Gantz \& Reinsel, 2011), so big data has brought great changes in thinking, business and management throughout society (Beyer \& Laney, 2012). Personalized recommendation, an important research direction of big data, has been recently studied in all walks of life (Abbas, Bilal, Zhang, \& Khan, 2015; Chang, Huang, \& Lai, 2014; Chung, 2014; Qian, Feng, Zhao, \& Mei, 2014). By studying users' character and analyzing users' behavior, information reflecting users' interest is currently recommended. The personalized recommendation technology includes content-based recommendations, user (item)based collaborative filtering recommendation and association rule-based recommendation, etc.

The tool of big data analysis can also be used to study behavior modification of metro construction, by combining the traditional BBS approach with personalized recommendation, then specific behavior modification content is accurately recommended to workers with different characters. Based on this, a behavior modification system of metro construction (BMSMC) is designed with data sources of site photos, which reflect workers' unsafe behavior and is to be matched with behavior modification content according to workers' characters based on personalized recommendation mechanism. In this way, workers can learn real-time unsafe behavior knowledge on site and the effectiveness of behavior modification could be improved. Finally, the system validity is verified by an index, named "unsafe behavior rate, $S$ ".

\section{Mechanism of content recommendation in behavior modification}

As for metro construction behavior modification, content is from site photos shot during daily safety inspection and safety check in construction site. These photos reflect worker's unsafe behavior (Guo, Luo, Jiang, \& Xiong, 2015; Xu \& Luo, 2014). By processing these pictures with their semantic information, test questions are generated.

Content-based recommendation is an important method for personalized recommendation (Balabanović \& Shoham, 1997; Pazzani \& Billsus, 2007; Popescul, Pennock, \& Lawrence, 2001), originally derived from the fieldinformation acquisition, which plays an important role in the field of information retrieval and information filtering (Khrib, Jemn, \& Nasraoui, 2009). Compared to traditional information retrieval, content-based recommendation con- siders the interest description files of different users, which is the user-interest model. Its basic idea is to filter information by calculating the similarity between information content (text files) with user's interests instead of relying on user's opinions on projects (Musto, 2010).

The process of pushing behavior modification content by content-based recommendation includes three steps: Firstly, extract the feature information from semantic information containing in behavior modification contents by content analyzer, which include types of unsafe behavior, construction phases, as well as the difficulty coefficient of tests. Secondly, collect worker's attribute information, including work types, construction tasks, and information collected in the behavior modification process, such as scores of the safety-level test and behavior modification test. The feedback is extracted by files investigator-learners. Finally, the key step, establish the relevance between feature information of workers and content through filter elements, then recommend the most relevant behavior modification content to correlated workers.

2.1 Corresponding rules between types of unsafe behavior and worker's work types

Firstly, 17 types of 522 critical unsafe behaviors are identified according to safety standards, operating rules, accident cases and expert experience to form the list of unsafe behavior (Guo, Luo, Jiang, \& Xiong, 2015). Unsafe behavior is extracted from site photos based on the list, partial content of which is shown below:

1) Not wearing antiskid shoes during work;

2) Not wearing safety belt when working at the height of more than $2 \mathrm{~m}$;

3) Climbing up and down the scaffolding without any protection;

4) Standing above the scaffolding but not putting enough boards;

5) Scaffolders don't set up cross bridging.

Secondly, one type of attribute information of workers (work types) is defined. The eight traditional construction work types in China consist of the carpentry, steel bar setter, plasterer, masonry worker, concreter, scaffolder, painter and waterproofing worker. The operators of construction machines consist operators of cranes, excavators, bulldozers, various other machine handles, electricians, cement workers, scaffold setters, and steel reinforcement fabricators. Each type of work should be clearly differentiated, for example, the rigging worker is not crane driver or signal worker, but one focus on tasks such as tying sling bundles and hooking. Therefore, workers can choose their corresponding work types before carrying out behavior modification.

Finally, the types of unsafe behavior are matched with worker's work types. Certain types of unsafe behavior, such as scaffolding and form work, may correspond to the 
specific work types, like scaffolder, form fixer while some may correspond multiple work types, such as lifting may involve crane driver, rigging worker and signal worker, also, there are unsafe behavior corresponding to all work types, such as one type of unsafe behavior in construction civilization, named "smoking freely on construction site", which almost exists for all workers in metro construction. The partial relevance between types of unsafe behavior and work types is shown in Table 1.

Table 1

Partial Relevance between Types of Unsafe Behavior and Worker's Work Types

\begin{tabular}{lcc}
\hline Unsafe behavior & $\begin{array}{c}\text { Type of unsafe } \\
\text { behavior }\end{array}$ & Work type \\
\hline Smoking freely on construction site & $\begin{array}{c}\text { Civilized } \\
\text { construction }\end{array}$ & All \\
Scaffolders don't set up cross bridging & Scaffolding & Scaffolder \\
Unstable excavator operation location & $\begin{array}{c}\text { Construction } \\
\text { equipment }\end{array}$ & $\begin{array}{c}\text { Excavator } \\
\text { driver }\end{array}$ \\
\hline
\end{tabular}

2.2 Corresponding rules between construction phases and worker's construction tasks

According to the standards for different work of rail transportation in different cities (Beijing, Chongqing, etc.), metro construction work breakdown structure (MCWBS) is formed. Metro construction phases are divided into unit work, sub-unit work, division work, sub-division work and subentry work. Figure 1 shows partial MCWBS of metro station, as a unit work. Unsafe behavior photos being collected, the construction phase is determined according to the acquisition time.

On the other hand, in order to know the actual construction progress, the construction date is recorded before workers participate in behavior modification, then corrected content generated from different construction phases in accordance with workers' specific construction tasks are assigned to the workers.

2.3 Corresponding rules between difficulty coefficient and worker's testing scores

Behavior modification content comes from on-site photos reflecting worker's unsafe behavior (Guo, Luo, Jiang, \& Xiong, 2015). System testing based on visual language is set as the behavior modification process with corresponding unsafe behavior as correct answer, and randomize other unsafe behavior as interference option. Then difficulty coefficient is designed in three levels (1-3), according to different question types (like comparison questions which contains two photos, and true or false questions which only contains one photo belonging to different types) and different answer settings (containing two, three or four

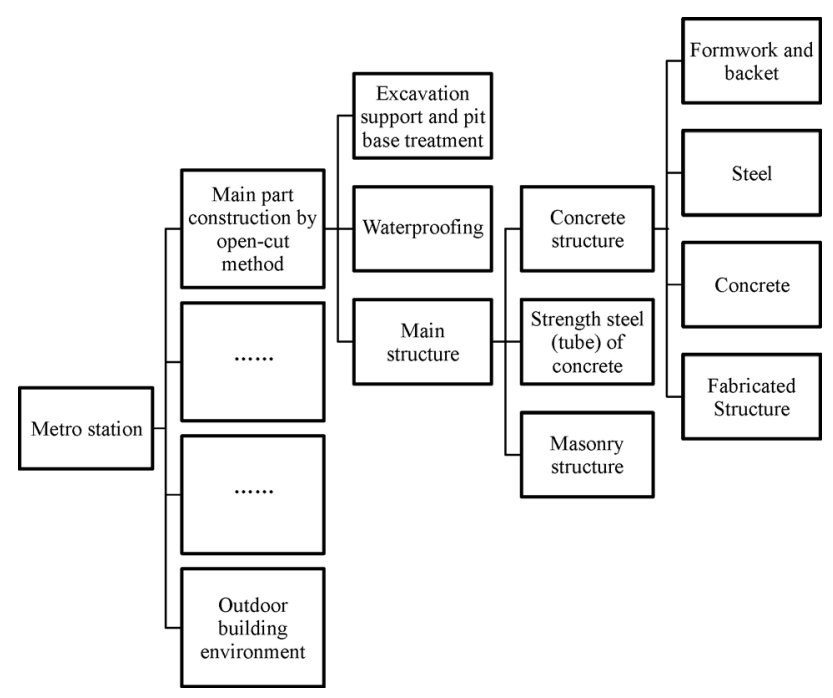

Figure 1. Partial MCWBS of metro station.

options). So the difficulty gradually increases for workers with better understanding.

Worker's test scores include safety-level test scores and behavior modification test scores. The latter is obtained when workers finish their behavior modification process, a maximum score of which is 100 . The safety-level test aims to capture worker's safety attitude, and it adopts the form of questionnaire by Likert (Likert, 1932), with number 1 to 5 respectively corresponding to "strongly oppose, oppose, neutral, agree and strongly agree". To avoid deviation of worker's perceptibility, the answer has been redesigned for each question, like my workmate and I think complying with the right rules of operation can avoid accidental injury, including five options that are "absolutely not, generally not, sometimes, generally, absolutely" to ensure the semantics being clearly expressed. There are 25 similar questions, and the final score is the average testing scores of all questions.

The difficulty coefficient is determined in accordance with worker's test scores. The process is shown in Figure 2. For the workers who participate in behavior modification for the first time, behavior modification content with different difficulty coefficients based on the safety-level test scores will be pushed; for those re-participants, ones corresponding to their last behavior modification test scores will be pushed.

\section{Behavior modification system for metro construction}

Based on mechanism of personalized content recommendation for behavior modification, the BMSMC is developed to facilitate the workers' participation. This system is designed as an APP on smart phone platform. The major functions are shown as below: 


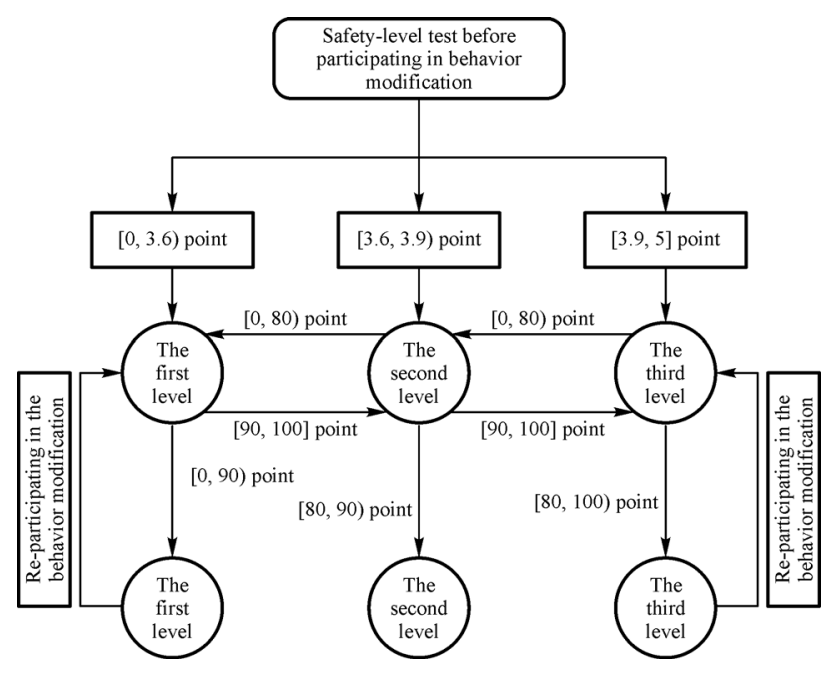

Figure 2. The corresponding diagram between difficulty coefficient and worker's testing scores.

- System notification pushing. According to the modification frequency of worker's participation and current schedule changes, the system pushes notification to remind workers to enter for behavior modification by the APP.

- Modification record query. After entering the system, workers can query their past participation records.

- Worker's information query. Workers can browse their personal information (including work unit, work group, work type, qualification, etc.) in the system.

- Safety-level test. When workers first enter the system, their safety level is judged by questionnaires, and then relevant content from the database is pushed to the worker.

- Data intelligent analysis. This function is the core part of this system. In the system, the relevance between behavior modification content and workers is to be analyzed, with the results of which different types of unsafe behavior and work types could be matched, so could the construction phases with worker's construction tasks, as well as the difficulty coefficient with worker's test scores, as shown in Figure 3.

- Behavior modification content pushing. After data intelligent analysis is complete, the system generates behavior modification content that conforms to the worker's characteristics.

- Modification results query. After system testing, workers can browse the test scores to check if they master the safety knowledge or not.

\section{Case study}

4.1 General information of the construction site for application

One metro station of the Wuhan Rail Transit Line 3 was set

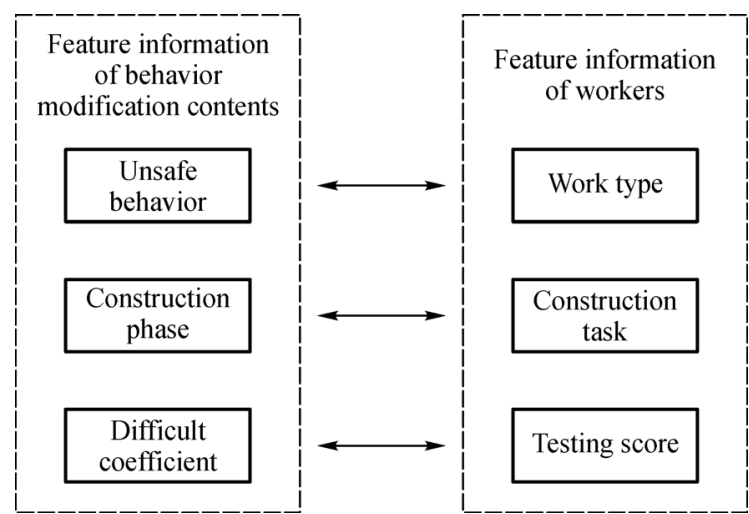

Figure 3. The relevance feature information between behavior modification content and workers.

as BMSMC application site, in which limited construction space, large traffic flow, interference of numerous pipelines, difficulty in dewatering and other typical construction problems were encountered. Workers faced more complicated construction environment, which led to more potential behavioral risks during construction.

\subsection{Application effect analysis}

Unsafe behavior rate $S$ is introduced as statistical indicator to verify the effectiveness of this system, which can quantify worker's unsafe behavior and draws lessons from safety index measurement (Chen \& Tian, 2012; Li, Lu, Hsu, Gray, \& Huang, 2015). $S$ is equal to the number of a team unsafe behavior occurrences in the completion of a specific task in unit time divided by total number of workers in the team. Calculation formula is as follows:

$$
S=\frac{N_{\mathrm{us}}}{N} \times 100 \%
$$

where $S$ is unsafe behavior rate, $N_{\text {us }}$ is unsafe behavior person-time per hour, and $N$ is the total worker number.

On-site behavioral observation had been carried out once a week (two hours) for 23 weeks continuously. The observed targets were two teams (20 workers) of scaffolders, one team participated in behavior modification on application construction site while the other not. The documented results are shown in Figure 4, in which the solid line represents $S$ change of the scaffolders on application construction site; the dashed line represents $S$ change of the scaffolders on other construction sites not participating in behavior modification. The first six-weeks were baseline phase that workers of these two sites did not participate in the behavior modification. During the time, the average unsafe behavior rate (in percentage) on application construction site is $\overline{S_{1}}=63.9 \%$, standard deviation is $\sigma_{1}=0.184$; at the same time, the average unsafe behavior rate on the other site is $\bar{S}_{2}=59.6 \%$, standard deviation is $\sigma_{2}=0.199$. Therefore, data differ- 


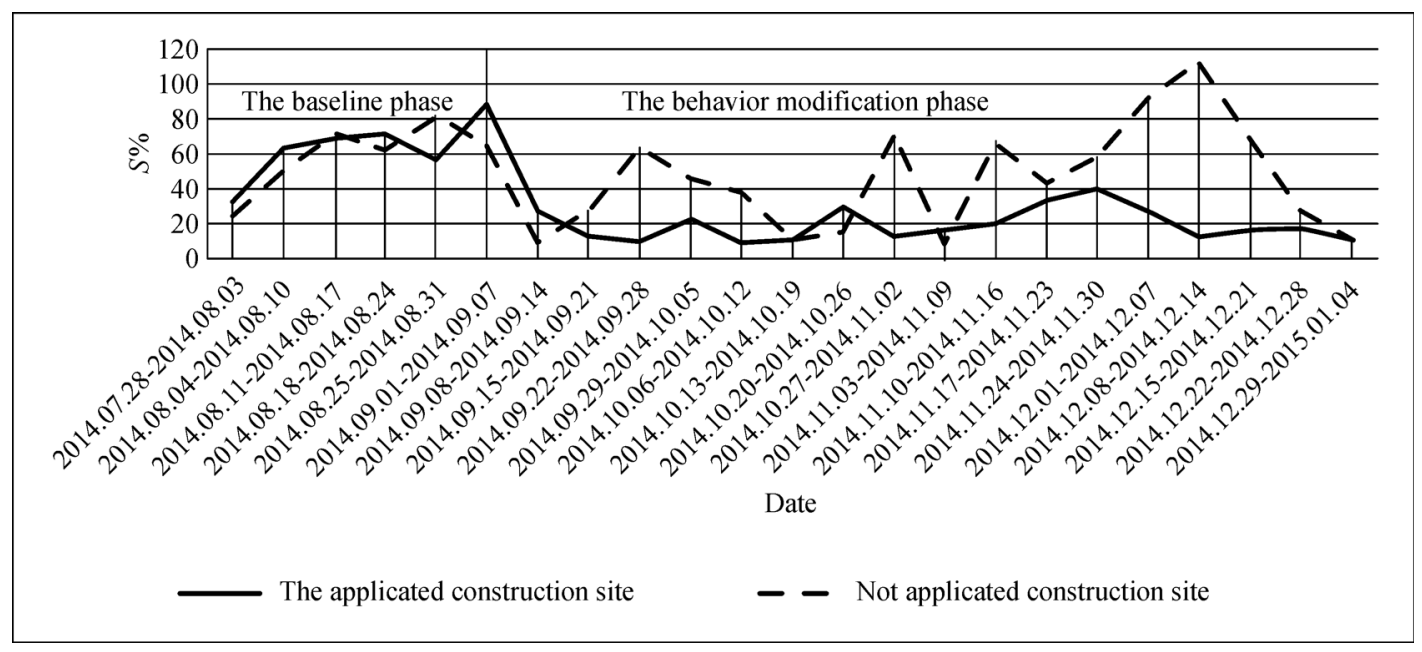

Figure 4. Change curve of worker's unsafe behavior rate.

ence between these two teams is insignificant. From the 7 th week to the 23th week, the team of scaffolders on this site participated in behavior modification. At this phase, the average unsafe behavior rate on this site is $\bar{S}_{1}^{\prime}=19.6 \%$, standard deviation is $\sigma_{1}^{\prime}=0.092$, while the average unsafe behavior rate of the other site is $\bar{S}_{2}^{\prime}=45.5 \%$, standard deviation is $\sigma_{2}^{\prime}=0.311$. By comparison of the results above, it can be seen that the unsafe behavior rate $S$ dropped $69.3 \%$ after the application construction site workers involve in behavior modification, and decreased $56.9 \%$ compared with the other group that without participating in behavior modification. Moreover, the unsafe behavior shows significantly less fluctuation and almost maintain at a low level. It indicates that the BMSMC could effectively reduce worker's unsafe behavior.

\section{Conclusions}

In this paper, the content-based personalized recommendation was used to investigate the mechanism of content recommendation for behavior modification in metro construction. The study found out the relevance between types of unsafe behavior and worker's work types, construction phases and worker's construction tasks, as well as difficulty coefficient of the tests and worker's test scores.

The BMSMC was developed based on the mechanism above. By intelligent analysis of the system, content of the behavior modification from the huge amounts of data could be pushed in accordance with the worker's characteristics. Then a construction site of metro station of the Wuhan Rail Transit Line 3 was selected as a demonstration site for application of this system. Moreover, unsafe behavior rate $S$ was imposed as an evaluation index, and statistical results verified the effectiveness of the index and the system.
By content-based personalized recommendation, behavior modification content could be pushed to different types of workers, but not for specific one. Personalized recommendation includes collaborative filtering recommendation and association rules recommendation, etc. Therefore, the future work is, with these recommendation technologies, to explore more targeted methods for worker's behavior modification.

\section{References}

Abbas, A., Bilal, K., Zhang, L., \& Khan, S. U. (2015). A cloud based health insurance plan recommendation system: A user centered approach. Future Generation Computer Systems, 43-44, 99-109

Azar, E. R., \& McCabe, B. (2012). Automated visual recognition of dump trucks in construction videos. Journal of Computing in Civil Engineering, 26, 769-781

Balabanović, M., \& Shoham, Y. (1997). Fab: Content-based, collaborative recommendation. Communications of the ACM, 40, 66-72

Beyer, M. A., \& Laney, D. (2012). The Importance of 'Big Data': A Definition. Stamford, CT: Gartner

Chang, H. Y., Huang, S. C., \& Lai, C. C. (2014). A personalized IPTV channel-recommendation mechanism based on the MapReduce frame work. Journal of Supercomputing, 69, 225-247

Chen, D., \& Tian, H. (2012). Behavior based safety for accidents prevention and positive study in China construction project. Procedia Engineering, 43, 528-534

Chen, D., \& Ren, D. (2015). Behavior based safety (BBS) for accident prevention and positive study in construction enterprise. In: 2015 International Conference on Management Engineering and Management Innovation (ICMEMI-15). Amsterdam: Atlantis Press, 50-57

Choudhry, R. M. (2014). Behavior-based safety on construction sites: A case study. Accident Analysis \& Prevention, 70, 14-23

Chung, K. Y. (2014). Effect of facial makeup style recommendation on visual sensibility. Multimedia Tools and Applications, 71, 843-853 
Gantz, J., \& Reinsel, D. (2011). Extracting value from chaos. IDC Iview, $1142,9-10$

Geller, E. S. (2000). The Psychology of Safety Handbook. Boca Raton: CRC Press LLC

Guo, S., Luo, H., Jiang, X., \& Xiong, C. (2015). Metro worker's behavior safety knowledge visualization research. China Safety Science Journal, 25, 140-145

Han, S., \& Lee, S. (2013). A vision-based motion capture and recognition framework for behavior-based safety management. Automation in Construction, 35, 131-141.

Heinrich, H. W., Petersen, D., \& Roos, N. (1950). Industrial Accident Prevention. New York: McGraw-Hill

Khrib, M. K., Jemni, M., \& Nasraoui, O. (2009). Automatic recommendations for e-learning personalization based on web usage mining techniques and information retrieval. Educational Technology \& Society, 12(4), 30-42

Li, H., Lu, M., Hsu, S. C., Gray, M., \& Huang, T. (2015). Proactive behavior-based safety management for construction safety improvement. Safety Science, 75, 107-117

Likert, R. (1932). A technique for the measurement of attitudes. Archives of Psychology, 22(140), 1-55

Lingard, H., \& Rowlinson, S. (1997). Behavior-based safety management in Hong Kong's construction industry. Journal of Safety Research, 28(4), 243-256

Lingard, H., \& Rowlinson, S. (2005). Occupational Health and Safety in Construction Project Management. New York: Spon Press

Liu, S. (2015). Wuhan metro construction in 2015 [Online message]. Sina Hubei. Retrieved on July 23, 2015 from http://hb.sina.com.cn/ news/b/2015-01-11/detail-icczmvun4883904.shtml (in Chinese)

Mayer-Schönberger, V., \& Cukier, K. (2013). Big Data: A Revolution That Will Transform How We Live, Work, and Think. New York: Houghton Mifflin Harcourt

Musto, C. (2010). Enhanced vector space models for content-based recommender systems. In: Proceedings of the Fourth ACM Conference on Recommender Systems. Barcelona: ACM, 361-364

Pazzani, M. J., \& Billsus, D. (2007). Content-based recommendation systems. In: Brusilovsky, P., Kobsa, A., \& Nejdl, W., eds. The Adaptive Web. Berlin: Springer, 325-341

Popescul, A., Pennock, D. M., \& Lawrence, S. (2001). Probabilistic models for unified collaborative and content-based recommendation in sparse-data environments. In: Proceedings of the 17th Conference on Uncertainty in Artificial Intelligence. San Francisco: Morgan Kaufmann Publishers Inc, 437-444

Qian, X., Feng, H., Zhao, G., \& Mei, T. (2014). Personalized recommendation combining user interest and social circle. IEEE Transactions on Knowledge and Data Engineering, 26(7), 17631777

Shrestha, K., Shrestha, P. P., Bajracharya, D., \& Yfantis, E. A. (2015). Hard-hat detection for construction safety visualization. Journal of Construction Engineering, 2015, 1-8

Smith, G. R. (1999). A behavior-based approach to construction: Applied behavior analysis for construction safety. Implementation of Safety and Health on Construction Sites, 337

Teizer, J., \& Vela, P. A. (2009). Personnel tracking on construction sites using video cameras. Advanced Engineering Informatics, 23(4), 452462

Xu, S., \& Luo, H. (2014). A behavior safety training system based on visual language. Journal of Civil Engineering and Management, 31 (3), 51-55, 77

Zhang, M., \& Fang, D. (2013). A continuous behavior-based safety strategy for persistent safety improvement in construction industry. Automation in Construction, 34, 101-107

Zhou, X. (2014). Situation of current development of domestic urban rail transit and problems to be concerned [Online forum paper]. World Rail Traffic Net. Retrieved on July 23, 2015 from http://rail.ally.net. cn/special/2014/0721/3438.html (in Chinese) 